\title{
RESTORASI CITRA MENGGUNAKAN JARINGAN SARAF TIRUAN (HOPFIELD)
}

Oleh:

\section{Silfia Rifka}

Staf Pengajar Teknik Elektro Politeknik Negeri Padang

\begin{abstract}
The final goal of restoration is image improvement. In general, restoration to degradation modeling and implementation of invers process to get real image. Hopefield method in neural network restoration of image is done by parameters approximation in neural network modeling and reconstruction of degradation image to get real image. In this paper, this method is used image restoration which combines with Gaussian Blur, Uniform Blur and Gaussian Noise.

The restoration process using this method take place really fast and suitable to defects restoration of recorder device which recognize the cause of defects and high process speed is needed.
\end{abstract}

Keyword : Image Restoration, Hopfield Network, Gaussian

\section{PENDAHULUAN}

Disini citra mengacu pada fungsi intensitas cahaya dua dimensi $\mathrm{x}(\mathrm{a}, \mathrm{b})$. Jika kuantitas dari intensitas cahaya adalah positif dan juga kecerahan maksimum dari citra dibatasi oleh sistem pencitraan, $\mathrm{x}(\mathrm{a}, \mathrm{b})$ adalah terbatas, real dan fungsi non-negatif.

$0 \leq x(a, b) \leq A$

Dengan A adalah kecerahan maksimum citra.

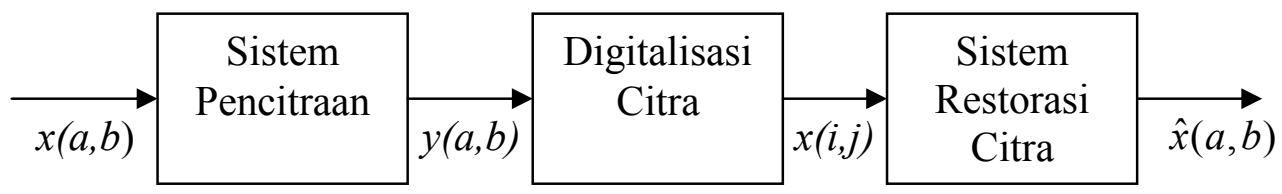

\section{Gambar 1. Sistem Restorasi Citra Digital}

Gambar 1 menunjukkan sebuah sistem restorasi citra digital yang terdiri dari tiga subsistem : sebuah sistem pencitraan, digitalisasi citra, dan sistem restorasi citra. Sistem pencitraan yang terdiri dari sebuah sistem optik dan piranti perekam, adalah sumber utama dari degradasi. Untuk dapat mengolah citra dengan komputer, citra dicuplik dan dikuantisasi oleh pendigitalan citra , yang menyumbangkan terjadinya degradasi citra karena kesalahan kuantisasi.

Selama lebih dari 20 tahun beberapa metode restorasi citra telah diperkenalkan, seperti Invers Filter, Wiener filter, Kalman Filter dan juga beberapa model lainnya. Kekurangan yang utama dari kebanyakan algoritma 
restorasi dari citra adalah kompleksitas perhitungannya, sehingga kemudian banyak dilakukan penyederhanaan. Sebuah sistem jaringan saraf tiruan, yang dapat melakukan perhitungan dengan cepat dipandang sangat menarik, khususnya untuk restorasi citra dan pengolahan citra pada umumnya.

Pada bagian ini disajikan sebuah algoritma jaringan saraf tiruan untuk merestorasi citra dengan aras keabuan, yang didegradasi oleh fungsi blur. Algoritma ini didasarkan pada model yang dijabarkan dengan menggunakan simle-sum number, atau penjumlahan angka. Citra yang akan direstorasi adalah citra yang didegradasi oleh fungsi tidak berubah ruang dan noise.

Prosedur restorasi citra terdiri dari dua tahap:

1. Taksiran /perkiraan dari parameter-parameter model jaringan saraf

2. Rekonstruksi citra

Pertama parameter dihitung dengan membandingkan fungsi energi dari jaringan saraf dengan fungsi error. Kemudian algoritma restorasi diterapkan menggunakan algoritma iteratif untuk meminimalkan fungsi energi dari jaringan saraf. Karena sifat fault tolerant dan kemampuan perhitungan, maka dengan pendekatan ini akan dihasilkan citra yang berkualitas.

\section{METODE PENELITIAN}

Metode Penelitian yang dilakukan adalah:

1. Studi literatur yang berhubungan dengan ruang lingkup penelitian.

2. Pembuatan program kemudian melakukan pengujian dan analisa dari hasil yang didapatkan.

\section{Model degradasi citra}

Dalam teknik restorasi citra diperlukan adanya suatu pemodelan citra. Gambar 2 menunjukkan sebuah model perusakan citra kontinyu-linear.

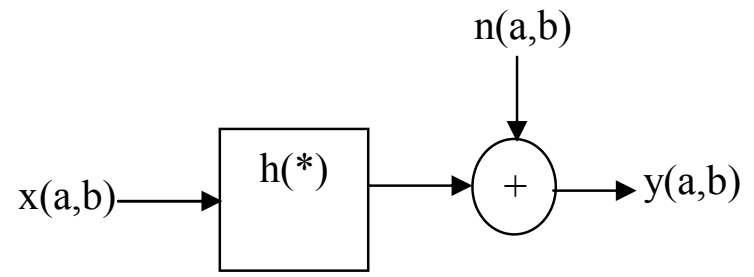

Gambar 2. Model Perusakan Citra Kontinyu-Linear

Ini diasumsikan bahwa citra kabur dapat dimodelkan sebagai superposisi dengan sebuah tanggapan impuls $h(*)$ dan ditambahkan derau pada keluarannya. Dalam hal ini citra dimodelkan dengan :

$$
\begin{array}{r}
y(a, b)=\iint_{-\sim-\sim}^{\tilde{\int}} h(a, b ; \alpha, \beta) x(\alpha, \beta) d \alpha d \beta \\
+n(a, b)
\end{array}
$$

dengan

$h(a, b ; \alpha, \beta)=$ fungsi blur atau fungsi impulse-response

$$
\begin{array}{ll}
n(a, b) & =\text { derau } \\
x(\alpha, \beta) & =\text { citra asli } \\
y(a, b) & =\text { citra kabur }
\end{array}
$$

Jika sistem tanpa perubahan dimensi, fungsi blur dapat dituliskan sebagai berikut :

$$
h(a, b ; \alpha, \beta)=h(a-\alpha, b-\beta
$$

Disini model pengaburan citra akan difokuskan pada model linear tanpa perubahan dimensi.

Seperti ditunjukkan pada gambar 1., keluaran dari sistem pencitraan adalah citra yang teramati kemudian didigitalkan oleh sebuah pendigitalan citra, baik secara runag dan amplitudo, kemudian memebrikan masukan bagi sistem restorasi. Untuk suatu sistem restorasi citra diskrit, objek dari restorasi adalah untuk menghasilkan citra digital 
yang merupakan perkiraan dari citra asli yang didigitalkan secara sempurna. Oleh karena itu penting untuk mengkonversi model degradasi kontinyu menjadi diskrit. Ini dapat dilakukan dengan pemotongan (truncating) dan pencuplikan (sampling) citra dan fungsi blur ke dalam bentuk matrik dua dimensi, asal saja mempunyai nyquist rate dan truncation error cukup kecil. Citra biasanya dibatasi dalam daerah intensitas 0 sampai $\mathrm{M}$, dengan $\mathrm{M}$ adalah bilangan bulat, misalnya 255 .

Jika fungsi blur tanpa perubahan dimensi $h(*)$ dapat dituliskan sebagai konvolusi atas sebuah matrik kecil KxK ( $\mathrm{K}$ adalah bilangan bulat ganjil), model kontinyu (1) dapat dituliskan dalam bentuk diskrit sebagai berikut :

$$
\begin{aligned}
y(i, j)= & x(i, j) * h(i, j)+n(i, j) \\
= & \sum_{k=-K}^{K} \sum_{l=-K}^{K} x(i-k, j-l) h(k, l)+n(i, j) \\
& +n(i, j)
\end{aligned}
$$

dengan i dan $\mathrm{j}$ bilangan bulat, * merupakan operator konvolusi dan $\mathrm{K}=(\mathrm{k}-1) / 2$. Model degradasi diskrit (2) seringkali diekspresikan dalam bentuk matriks-vektor sebagai :

$Y=H X+N$

dengan

$\mathrm{H}=$ matriks pengkabur (blurrung matrix)

$\mathrm{N}=$ derau putih

$\mathrm{X}=$ citra digital

$\mathrm{Y}=$ citra rusak (degraded image)

Vektor X dan Y serupa dengan Vektor

N. Persamaan di atas diambil dengan asumsi model perusakan adalah linier tanpa perubahan dimensi.

\section{Penyajian citra}

Jaringan saraf yang mempunyai neuron dalam jumlah yang sangat banyak digunakan untuk menyajikan citra dengan skala keabuan. Model ini terdiri dari $\mathrm{L}^{2} \times \mathrm{M}$ neuron yang saling terhubung satu sama lain dengan $\mathrm{L}$ adalah ukuran citra dan $\mathrm{M}$ adalah nilai maksimum dari fungsi skalan keabuan.

Citra disajikan oleh fungsi skala keabuan $\{x(i, j)$ dengan $1 \leq i, j \leq L\}$, dengan $\mathrm{x}(\mathrm{i}, \mathrm{j})$ adalah bilangan bulat positif yang menunjukkan tingkat keabuan pada piksel(i,j). Misalkan vektor $\mathrm{V}=\left\{v_{i, k}\right.$, dengan $1 \leq i \leq L^{2}$ dan $1 \leq k \leq M\}$ dengan $v_{i, k}$ bernilai 1 untuk hubung dan bernilai 0 untuk tak hubung, yang menandakan keadaan neuron $\mathrm{i}, \mathrm{k}$. Citra dengan fungsi skala keabuan digambarkan sebagai penjumlahan neuron yang mewakilinya:

$$
x(i, j)=\sum_{k=1}^{M} V_{m, k}
$$

dengan

$$
m=(i-1) x L+j
$$

Jika fungsi skala keabuan disajikan oleh $\mathrm{M}$ neuron, misalkan diambil nilai $\mathrm{M}$ adalah 100, maka terdapat 100 neuron yang bernilai 1 dan terdapat $\frac{M !}{100 !(M-100) !}$ kemungkinan.

Dengan cara ini jika terdapat kesalahan nilai maka sebuah neuron tidak akan menyebakan error yang besar. Dengan cara penyajian seperti ini terdapat :

$$
\prod_{i=1}^{L} \prod_{j=1}^{L} \frac{M !}{x(i, j) !(M-x(i, j)) !}
$$

Keadan stabil untuk citra dengan ukuran L x L. Banyaknya kemungkinan keadaan stabil ini membuat jaringan memiliki lebih banyak peluang untuk mencapai penyelesaian. Dengan menggunakan model ini, akan diperoleh keuntungan yaitu system bersifat fault 
tolerance dan akan lebih cepat menuju penyelesaian.

Dalam model ini setiap neuron $(\mathrm{i}, \mathrm{k})$ secrara acak dan asinkron menerima masukan dari semua neuron dan masukan bias.

$$
\mathrm{u}(\mathrm{i}, \mathrm{k})=\sum \sum \mathrm{T}_{\mathrm{i}, \mathrm{kj}, \mathrm{w}} \mathrm{w}_{, \mathrm{d}}+\mathrm{I}_{\mathrm{i}, \mathrm{k}} \ldots(5)
$$

dengan:

$T_{i, k i, j:}=$ bobot koneksi (interconnection strength) antara neuron (i,k) dan neuron $(\mathrm{j}, 1)$

$\boldsymbol{I}_{i k} \quad=$ masukan bias

Diasumsikan bahwa bobot koneksi mempunyai sifat :

$$
T_{i, k j, i}=T_{j, i j, k i} \text { dan } T_{i, k i k}=0
$$

Yang berarti bahwa bobot koneksi adalah simetris dan neuron mempunyai

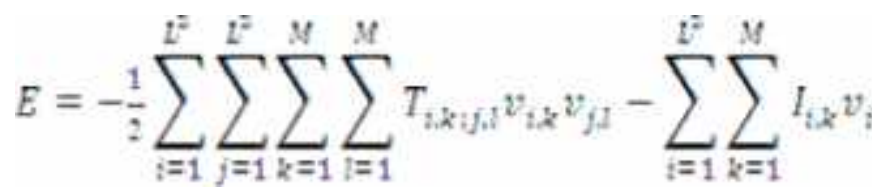

Dalam hubungannya dengan upaya untuk meminimumkan fungsi energy jaringan saraf tiruan, salah satu rumusan restorasi citra adalah meminimumkan fungsi kesalahan (error function) dari system, yang didefenisikan sebagai :

$$
E=\frac{1}{2}\|Y-H \hat{X}\|+\frac{1}{2} \lambda\|D \hat{X}\|^{2}
$$

self-feedback. Setiap $\mathrm{u}_{i, k}$ memberi masukan ke neuron yang berhubungan setelah adanya fungsi ambang :

$$
v_{i, k}=\mathrm{g}\left(\mathrm{u}_{\mathrm{i}, \mathrm{k}}\right)
$$

Dengan $\mathrm{g}(\mathrm{x})$ adalah fungsi tidak linear yang mengambil nilai :

$$
g(x)=\left(\begin{array}{l}
1 \\
0
\end{array} \begin{array}{l}
\text { jika } x \geq 0 \\
\text { jika } x<0
\end{array}\right.
$$

Dalam model ini setiap neuron diperbaharui dengan menggunakan kondisi terakhir neuron yang lain.

\section{Prediksi parameter model}

Fungsi energi jaringan saraf tiruan Hopfield dapat dituliskan sebagai persamaan $(8)$ 


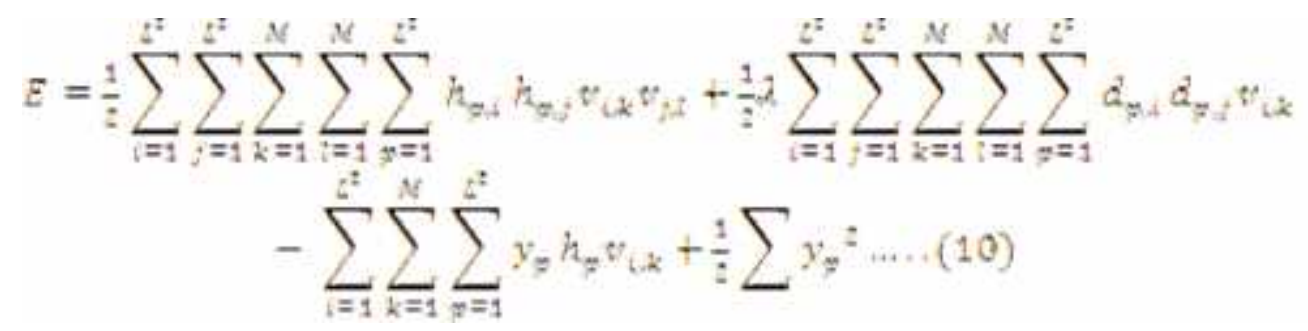

Dengan

persamaan (10) dan (8) serta mengabaikan $2 \sum y_{\mathrm{z}}^{2}$, akan diperoleh bobot koneksi :

$\mathrm{T}_{\mathrm{i}, \mathrm{k}, j, \mathrm{j}}=-\sum_{\mathrm{p}=1}^{\mathrm{L}^{2}} \mathrm{~h}_{\mathrm{p}, 1} \mathrm{~h}_{\mathrm{p}, \mathrm{j}}-\mathrm{h} \sum_{\mathrm{p}=1}^{\mathrm{L}^{2}} \mathrm{~d}_{\mathrm{p}, \mathrm{i}} \mathrm{d}_{\mathrm{p}, \mathrm{j}}$

Dan masukan pra sikap:

$\mathrm{I}_{\mathrm{i}, \mathrm{k}}=\sum_{p=1}^{\mathrm{L}^{2}} \mathrm{y}_{\mathrm{p}} \mathrm{h}_{\mathrm{p}, \mathrm{j}}$

dengan :

$\mathrm{T}_{\mathrm{i}, \text { tij }}=$ bobot koneksi antara neuron $(\mathrm{i}, \mathrm{k})$ dan $(\mathrm{j}, \mathrm{l})$

$I_{i k}=$ masukan bias

$\mathfrak{h}_{i, j} \quad=$ elemn matrik $\mathrm{H}$

$\mathrm{d}_{\mathrm{i}, \mathrm{j}}=$ elemn matrik $\mathrm{D}$

Pada persamaan (11) dan (12)

tampak bahwa bobot koneksi bebas terhadap subscript $\mathrm{k}$ dan 1 , serta masukan bias bebas terhadap subscript $\mathrm{k}$.

Dari persamaan (11) bobot koneksi ditentukan oleh fungsi blur tanpa perubahan dimensi, operator difrensial dan konstanta $\lambda$, sehingga $\mathrm{T}_{\text {, , k } ; j, 1}$ dapat dihitung tanpa kesalahan asal saja fungsi blur diketahui. Proses pembentukan bobot koneksi dalam restorasi citra ini berbeda dengan pembentukan bobot koneksi pada pengingat asosiatif, dimana bobot koneksinya dibentuk dari pola vector masukan (asli).

Berbeda dengan bobot koneksi, masukan bias ditentukan juga oleh citra terdegradasi. Jika citra hanya didegradasi oleh fungsi blur tanpa perubahan dimensi, maka masukan bias $\mathbf{I}_{i, k}$ dapat dihitung dengan sempurna. Akan tetapi

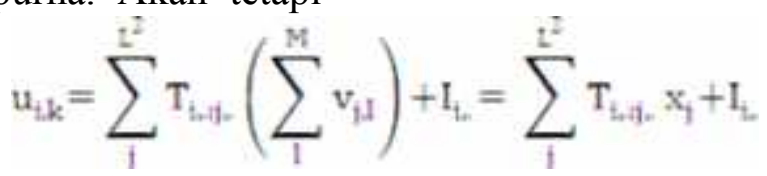

$I_{i, k}$ dipengaruhi juga oleh derau. Dengn mengganti $y_{p}$ dengan

$\sum_{i=1}^{z^{z}} h_{p i} x_{i}+n_{p}$ maka akan didapatkan:

$$
\begin{aligned}
I_{i, k} & =\sum_{p=1}^{L^{2}}\left(\sum_{i=1}^{L^{2}} h_{p, i} x_{j}+n_{p}\right) h_{p, i} \\
& =\sum_{p=1}^{L^{2}}\left(\sum_{j=1}^{t^{2}} h_{p, i} x_{j} h_{p}+\sum_{p=1}^{L^{2}} n_{p p} h_{p i d}(13)\right.
\end{aligned}
$$

Persamaan (13) memperlihatkan pengaruh dari derau. Tampak bahwa jika tidak ada derau maka parameter dapat diperkirakan dengan sempurna.

\section{Restorasi}

Dari persamaan (11) tampak bahwa bobot koneksi bebas dari subscript $\mathrm{k}$ dan 1 dan masukan bias (12) bebas dari subscript $\mathrm{k}$. hal ini berarti bahwa sejumlah $M$ neuron yang mewakili satu fungsi skala keabuan mempunyai bobot koneksi dan masukan bias yang sama, sejingga untuk tiap fungsi skala keabuan hanya diperlukan satu perangkat bobot koneksi dan masukan bias. Akibatnya dimensi matriks $\mathrm{T}$ dan I dapat direduksi sebesar factor $\mathrm{M}^{2}$.

Dari persamaan (5) seluruh masukan yang diterima oleh neuron ke $(\mathrm{i}, \mathrm{k})$ dapat dituliskan : 
Dengan $\mathrm{x}_{\mathrm{j}}$ adalah fungsi skala keabuan dari piksel ke j. Tanda "." Pada bagian subscript berarti bebas dari k. dari persamaan (14) terlihat bahwa kita dapat memakai bilangan decimal untuk menggantikan bilangan biner $\mathrm{v}_{\mathrm{i}, \mathrm{j}}$,

Karena bobot koneksi ditentukan oleh fungsi blur, operator Laplace dan konstanta , seperti tampak pada persamaan (11), jika fungsi blur bersifat local maka sebagian besar elemen bobot koneksi ( $\mathrm{T}$ ) bernilai 0 dan neuron terhubung secara local. Hal ini sangat bermanfaat untuk menghemat memori.

Berdasarkan nilai masukan $u_{i, k}$ keadaan neuron ke (i,k) dipengaruhi menurut aturan keputusan. Perubahan keadaan neuron ke $(\mathrm{i}, \mathrm{k})$ akan

$$
\begin{aligned}
& \Delta v_{i, k}=g\left(u_{i, k}\right)\left\{\begin{array}{l}
\Delta v_{i, k}=0 \\
\Delta v_{i, k}=1 \\
\Delta v_{i, k}=-1
\end{array}\right. \\
& x_{i}^{b a r u}=\left\{\begin{array}{c}
x_{i}^{l a m a}+\Delta v_{i k} \\
x_{i}^{l a m s}
\end{array}\right.
\end{aligned}
$$

Untuk membatasi fungsi skala keabuan pada nilai $0-255$, pada setiap langkah pembaharuan nilai $x_{i}$ barw harus diperiksa. Persamaan(14),(16) dan (17) memberikan algoritma yang ringkas, yang dapat dituliskan sebagai berikut :

1. Ambil citra terdegradasi sebagai nilai awal.

2. Piksel citra diperbaharui secara berurutan. Setiap piksel diperbaharui dengan menggunakan persamaan (14),(16), dan (17), secara berulang-ulang sampai tidak terjadi perubahan lagi, yaitu $\Delta E \geq 0$ atau $\Delta v_{i, k}=0$, dan kemudian dilanjutkan ke piksel berikutnya. menyebabkan perubahan fungsi skala keabuan seperti persamaan (15) berikut :

$$
x_{i}^{\text {bark }}=\left\{\begin{array}{c}
x_{i}^{\text {iama }} \quad j i k a \Delta v_{i, 2}=0 \\
x_{i}^{\text {tama }}+1 \text { jika } \Delta v_{i, 2}=1 \quad(15) \\
x_{i}^{\text {tama }}-1 \text { jika } \Delta v_{i, k}=-1
\end{array}\right.
$$

Dengan $\Delta v_{i, k}=v_{i, k}{ }^{\text {baru }}-v_{i, k}$ iama adalah perubahan keadaan pada neuron ke $(i, j)$, superscript baru dan lama menandai sesudah dan sebelum pembaharuan dan $\mathrm{x}_{\mathrm{i}}$ mewakili nilai skala keabuan dari $\mathrm{M}$ neuron. Dengan asumsi bahwa neuron dari jaringan saraf tiruan diperbaharui secara berurutan, prosedur pembaharuan dapat dirumuskan sebagai :

$$
\begin{aligned}
& \text { jika } u_{i, k}=0 \\
& \text { jika } u_{i, k}>0 \\
& \text { jika } u_{i, k}<0 \\
& \text { jika } \Delta E<0 \\
& \text { jika } \Delta E \geq 0 \ldots \ldots \ldots \ldots \ldots(16)
\end{aligned}
$$

3. Memeriksa fungsi energi. Jika energy tidak berubah lagi maka proses restorasi selesai. Jika masih berubah maka kembali ke langkah 2.

Perhitungan masukan $u_{i, k}$ dari neuron ke (i,k) dan perubahan energi $\Delta E$ dapat disederhanakan. Saat memperbarui fungsi skala keabuan yang sama secara berulang, masukan yang diterima oleh neuron ke (i,k) saat ini dapat dihitung menggunakan hasil sebelumnya :

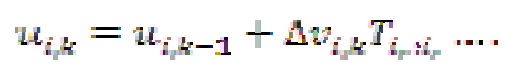

dengan $u_{i k-1}$ adalah masukan yang diterima oleh neuron ke (i,k-1). Perubahan energi $\Delta E$ yang disebabkan 
oleh perubahan keadaan neuron ke $(\mathrm{i}, \mathrm{k})$ dapat dihitung sebagai berikut :

$$
\Delta E=-u_{i_{k}, k} \Delta v_{i, k}-\frac{1}{2} T_{i_{*}, i_{F}}\left(\Delta v_{i, k}\right)^{2 \ldots}
$$

\section{HASIL RESTORASI}

Citra direstorasi citra dengan ukuran 128 x 128 piksel, dengan 256 skala keabuan. Disini digunakan model jaringan saraf tiruan dengan jumlah neuron $\mathrm{L}^{2}$, dengan $\mathrm{L} \times \mathrm{L}$ adalah ukuran citra. Masukan dari system ini adalah citra terdegradasi dan keluarannya adalah citra restorasi.

Citra hasil proses restorasi ini kemudian dibandingkan dengan citra asli. Untuk mengukur kualitas citra asli hasil restaorasi digunakan criteria fidelitas objektif yang ada, yaitu $\mathrm{e}_{\mathrm{rms}}$ dan $\mathrm{SNR}_{\mathrm{rms}}$.

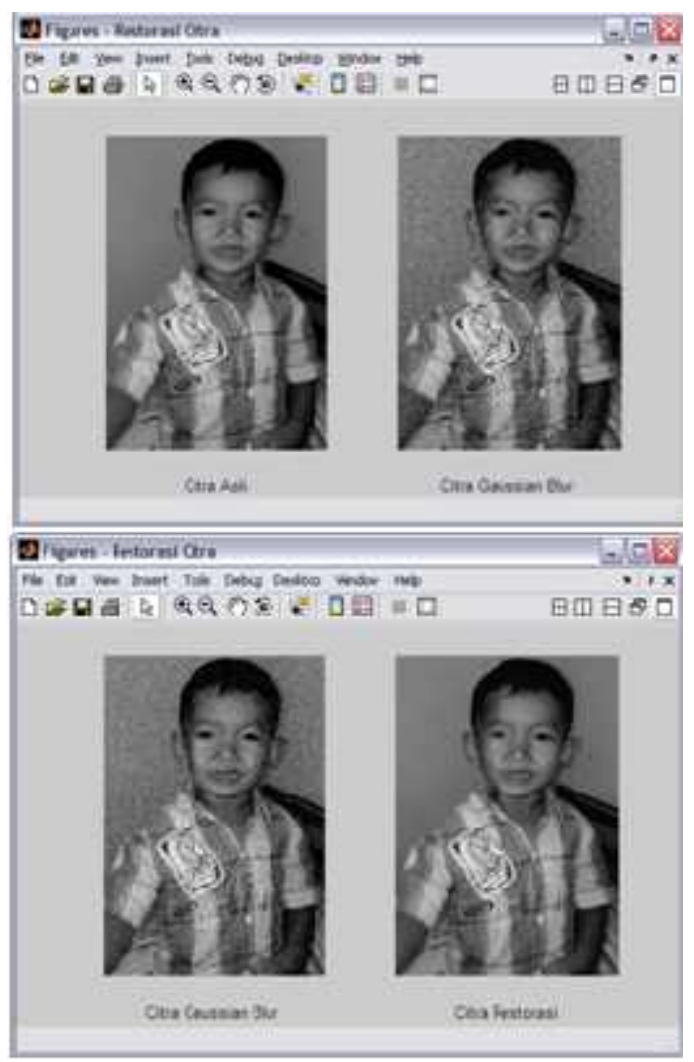

Gambar 3. Contoh citra hasil restorasi yang dikaburkan dengan Gaussian Blur dan noise ditambahkan derau Gaussian (Gaussian Noise) pada citra tersebut.

Gambar 3 menunjukkan restorasi citra menggunakan jaringan saraf tiruan. Pada proses restorasi citra ini digunakan Gaussian blur atau Uniform blur untuk mengeburkan citra asli, kemudian citra asli dikaburkan dengan menggunakan Gaussian noise dan Gaussian Blur. RMS (root mean square error) antara citra hasil restorasi dan citra asli sebesar 0.1 serta SNR sebesar 47,1. Grafik RMS terlihat pada gambar 4. Pada Gambar 5 terlihat bahwa citra hasil restorasi tidak sempurna. Citra-citra tersebut dikaburkan dengan Uniform blur dan ditambahkan derau kecil pada citra yang telah dikaburkan, dan dihasilkan RMS 11.8 dan SNR 26,6 seperti terlihat pada Gambar 6 .

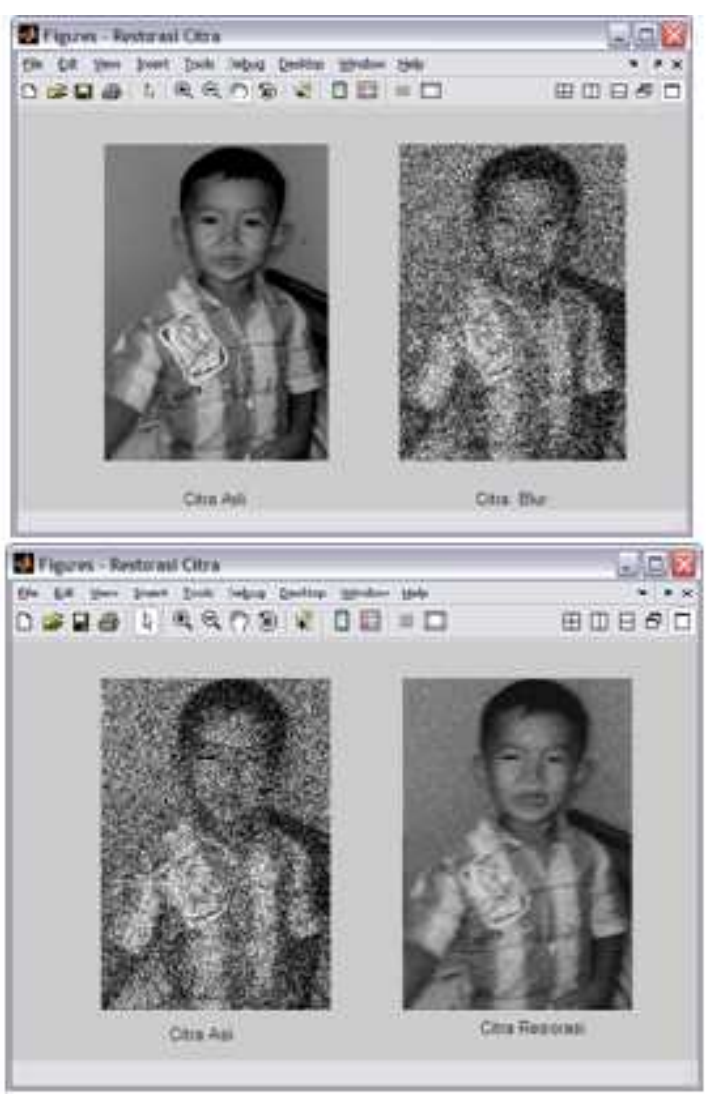

yang dikaburkan dengan Uniform Blur dan noise

Secara umum tampak bahwa citra yang dikaburkan dengan uniform blur 
memberikan hasil restorasi yang kurang sempurna dan memerlukan proses iterasi yang lebih lama. Sebaliknya terjadi pada citra yang dikaburkan dengan Gaussian Blur, dimana citra hasil restorasi sangat mendekati asli.

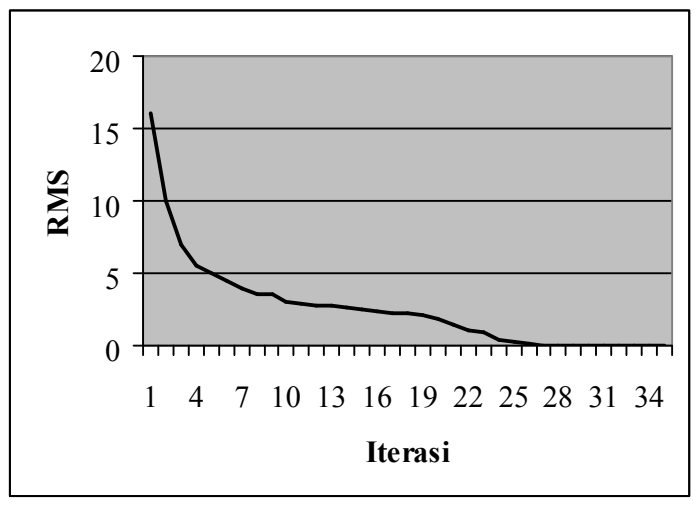

Gambar 4. Grafik fungsi RMS dari proses restorasi Gaussian blur dan noise

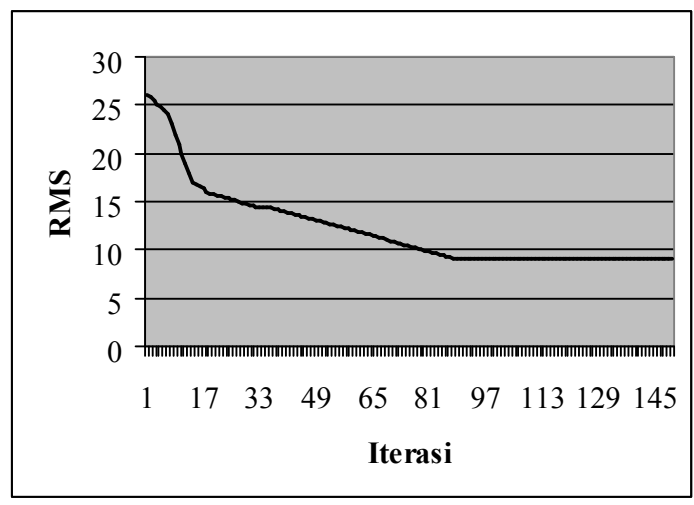

Gambar 6. Grafik fungsi RMS dari proses restorasi Uniform Blur dan Gaussian noise sudah diketahui penyebab cacatnya dan memerlukan proses yang cepat.

\section{DAFTAR PUSTAKA}

Arief Rahman, 2006, Jaringan Saraf Tiruan Teori dan Aplikasi, Andi, Yogyakarta

Bose, 1996, Neural Network Fundamental with Graph, Algortihms and Application, McGraw Hill, New York.

Rao, V dan Rogers, R.D., 1994, "Artificial Neural Network", IEEE, Computer Sociaty Press, California.

Haykin, S., 1994, Neural Network, A Comprehensive Foundation, Macmillan College Publishing Co., New York.

\section{KESIMPULAN}

1. Dengan metode jaringan saraf tiruan hanhya diperlukan fungsi kabur dan citra terdegradasi, tidak diperlukan adanya citra asli.

2. Proses restorasi dengan metode ini berlangsung dengan cepat sehingga sangat sesuai untuk merestorasicacat dari suatu peranti perekam yang 